\title{
A female surgeon's thoughts on gender attributes in surgery
}

\author{
Xueli Bai \\ Department of Hepatobiliary and Pancreatic Surgery, The First Affiliated Hospital, Zhejiang University School of Medicine, Hangzhou, China \\ Correspondence to: Xueli Bai. Department of Hepatobiliary and Pancreatic Surgery, The First Affiliated Hospital, Zhejiang University School of \\ Medicine, Hangzhou, China. Email: shirleybai@zju.edu.cn.
}

Submitted May 24, 2021. Accepted for publication Jun 03, 2021.

doi: 10.21037/hbsn-2021-14

View this article at: http://dx.doi.org/10.21037/hbsn-2021-14

There is a Chinese old saying that started in the 19th century: "A woman is vulnerable, but being a mother makes one strong". This seems to make sense, considering the status of women in society around a hundred years ago. None of us lived in that period, but we can imagine that women who lived back then might not have been obligated to work or assume a profession. Rather, it seemed more natural for them to do housework and teach their children at home. Being a mother is more like a sworn duty, perhaps similar to that of a doctor in the medical field. When I reflect on modern society, what I want to say is "women are not vulnerable, participating in medicine makes one stronger".

Each busy day, especially when standing on the operating table with a scalpel in my hand, I forget my identity as a woman. Apart from these moments, however, the impact of the identity and physiological attributes of being female permeate my profession as a surgeon.

I am certain that I am not the only female surgeon to wonder about the following questions from time to time: why should we talk about gender attributes in surgeons? What are the advantages and disadvantages of being a female surgeon? How do you become an excellent female surgeon?

Here, I am trying to answer these questions based on what I have seen, heard, and felt during the two decades of my surgical career.

\section{Q1: Why should we talk about gender attributes in surgeons?}

For the pioneer female surgeons of 200 years ago, this issue of being a woman and a surgeon was one of "to be, or not to be". Born in 1789, Margaret Ann Bulkley was considered to be the first female surgeon in the United Kingdom, but during the four decades of her surgical career, she disguised herself as the "beardless" James Miranda Steuart Barry. It was not until her autopsy report in 1865 that it was revealed she was actually a woman.

Over the past 200 years, women have made progress in the field of medicine. In 2019, the chief of the American Society of Clinical Oncology, the most influential oncology society in the world, was Dr. Monica M. Bertagnolli. Dr. Bertagnolli is a woman and a tenured professor of surgery at Harvard Medical School and chief of the Division of Surgical Oncology at Brigham and Women's Hospital. However, the same year, the Chinese College of Surgeons published the "Investigation Report on the Practice Status of Chinese Female Surgeons" [2019]. This investigation included surgeons from 30 different provinces, municipalities, autonomous regions, and countries. The results showed that women accounted for only $6.04 \%$ of the total number of surgeons. The majority of them were in thyroid and breast surgery (35.61\%), gastrointestinal surgery (19.55\%), and hepatobiliary and pancreatic surgery (13.67\%).

Over the past two centuries, female surgeons have striven to move forward. There have been indeed been many positive changes made in the surgical field, but the lingering limitations should be recognized. Gender discrimination still plays a role in the careers of female surgeons, but this obstacle will soon be overcome: "A person who holds the scalpel in hand is a surgeon, regardless of their gender".

\section{Q2: What are the advantages and disadvantages of being a female surgeon?}

Many female medical students ask me what kind of difficulties I face as a female surgeon. However, I think this 
question can be reframed in terms of what the advantages and disadvantages are of being a female surgeon, and a consideration on the individual level about how one decides whether he or she is suitable for this career.

The "Investigation Report on the Practice Status of Chinese Female Surgeons" [2019] showed that most female surgeons felt that they were at a disadvantage in terms of physical strength, family obligations, etc. In terms of advantages, most of them believed that they were more patient, considerate, and dexterous, and were able to injure patients less during operations than male surgeons.

Other interesting research has been conducted in this field over the years. A paper published in the British Medical fournal retrospectively analyzed a cohort of more than 104,000 patients who underwent surgery in Ontario, Canada from 2007 to 2015. The goal was to investigate whether the gender of surgeons played a role in general surgical outcomes. One controversial result was that the perioperative mortality rate of patients of female surgeons was $4 \%$ lower than that of patients with male surgeons. However, in terms of hospital readmissions and surgical complication rates, these two groups showed no significant differences (1).

In addition, female doctors tend to have more patientcentered communication. They usually spend more time with patients, asking patient opinions, and are more encouraging and reassuring when patients experience difficulties in mental health, lifestyle modification, social relations, or coping with stress (2). I believe these qualities are essential to good patient care.

\section{Q3: How to become an excellent female surgeon?}

Looking back on my personal experience, if it were not for my strong desire to help patients and my motivation to learn continuously, I never would have become a female surgeon, let alone an excellent female surgeon.

Thus, the question comes back to "how does one become an excellent female surgeon?".

First, my interest in medicine was the biggest driving force to succeeding in my career. When I filled out my college applications, I did not discuss my choices with anyone because all applications were for programs in medicine. It was a natural choice and not the result of weighing the pros and cons of different options: I did not want to go into any major if it was not medicine. I actually did not know much about surgery or the medical field at that time, despite having a pure passion for medicine. Today, however, I can identify the diseases from insidious symptoms, find operative spaces between numerous tiny vessels and nerves, and make the impossible become possible. The magic of the surgical profession has engrossed me for decades and my passion for this career has never wavered. This is why I believe that being passionate about medicine is the most important driving force for becoming a surgeon.

Secondly, one must be fully dedicated to medicine to overcome any obstacles. Compared with our male colleagues, female surgeons tend to face more challenges in their careers. In 2015, a study published in the fournal of the American Medical Association showed that female doctors were less likely to become tenured professors than were male doctors (11.9\% vs. 28.6\%) (3). Another study "Survey on the Occupational Status of Chinese Healthcare Workers" published by the Southern Weekly in March 2020 stated that women were facing greater pressure than were men who worked in the same position. A great portion of this pressure comes from having to balance the obligations of career and family, and thus female surgeons need to be extremely persistent and resilient on their career path in order to manage these problems and find an equilibrium.

Last but not least, leadership is the key to become an outstanding surgeon. To be an exceptional female surgeon, one should participate in the decision-making process, even for minor issues. One should also take initiative, foster a healthy working environment, and be adaptive to different situations (4).

I truly hope that more outstanding young people can join our team, regardless of gender. Being a surgeon is an extremely hard and stressful profession, but it can also bring an equal or greater amount of joy. The main prerequisite for this career is that one know what one is truly passionate about. Only people with a true love for medicine can be fully dedicated to this career and have the courage to face all of its difficulties. This love is a seed, which determines what kind of fruit will blossom in the future.

\section{Acknowledgments}

Funding: None.

\section{Footnote}

Provenance and Peer Review: This article was commissioned by the editorial office of Hepatobiliary Surgery and Nutrition. 
The article did not undergo external peer review.

Conflicts of Interest: The author has completed the ICMJE uniform disclosure form (available at https://hbsn. amegroups.com/article/view/10.21037/hbsn-2021-14/coif). The author has no conflicts of interest to declare.

Ethical Statement: The author is accountable for all aspects of the work in ensuring that questions related to the accuracy or integrity of any part of the work are appropriately investigated and resolved.

Open Access Statement: This is an Open Access article distributed in accordance with the Creative Commons Attribution-NonCommercial-NoDerivs 4.0 International License (CC BY-NC-ND 4.0), which permits the noncommercial replication and distribution of the article with

Cite this article as: Bai X. A female surgeon's thoughts on gender attributes in surgery. HepatoBiliary Surg Nutr 2021;10(3):370-372. doi: 10.21037/hbsn-2021-14 the strict proviso that no changes or edits are made and the original work is properly cited (including links to both the formal publication through the relevant DOI and the license). See: https://creativecommons.org/licenses/by-nc-nd/4.0/.

\section{References}

1. Park A. Researchers find women make better surgeons than men. TIMES, 2017-10-10.

2. Chen PW. Do women make better doctors? The New York Times, 2010-05-06.

3. Jena AB, Khullar D, Ho O, et al. Sex differences in academic rank in US medical schools in 2014. JAMA 2015;314:1149-58.

4. Columbus AB, Lu PW, Hill SS, et al. Factors associated with the professional success of female surgical department chairs: a qualitative study. JAMA Surg 2020;155:1028-33. 